\title{
РЕЙТИНГ УЧАСТКОВ С ДЕРЕВЬЯМИ НА КАДАСТРОВЫХ КВАРТАЛАХ ГОРОДА
}

${ }^{1}$ Мазуркин П. М., ${ }^{1}$ Кудряшова А. И.

${ }^{1}$ ФББОУ ВПО «Поволжский государственный технологический университет». Россия, Республика Марий Эл, 424000, г. Йошкар-Ола, пл. Ленина, д. 3. e-mail: Little-one7@yandex.ru; kaf_po@mail.ru

По классификации ООН среди 11 классов почвенного покрова первые три составляют травяной покров, древесно-кустарниковая растительность и леса. В городе им соответствуют три элемента растительного покрова: газоны, древесные насаждения (древостои) и кустарник обычный. Для выявления статистических закономерностей было принято зонирование городской застройки. Картографическими измерениями в ГИС «Карта 2011» г. Йошкар-Ола была выделена «Зона застройки многоэтажными жилыми домами». Рассмотрены параметры участков с деревьями: количество элементов разного уровня, площадь и периметр, коэффициенты абсолютной и относительной формы. Получены двухчленные уравнения ранговых распределений, проведен рейтинг и выбран лучший участок с деревьями по экологическим условиям.

Ключевые слова: город, кадастровые квартала, древостои, распределения, закономерности, рейтинг, лучший участок с деревьями.

\section{A RATING OF LOTS OF TREES ON THE CADASTRAL DISTRICTS OF THE CITY}

${ }^{\mathbf{1}}$ Mazurkin P. M., ${ }^{1}$ Kudryashova A. I.

${ }^{1}$ Volga state technological University. 3, Lenin sq. Republic of Mari El, Yoshkar-Ola, 424000, Russia.e-mail: Little-one7@yandex.ru; kaf_po@mail.ru

According to UN classification among 11 classes of soil cover the first three are grass, trees and shrubs and forests. In the city they correspond to the three elements of vegetation: lawns, tree plantings (trees) and shrub normal. To identify the statistical-sky laws were adopted, the zoning of urban development. Map measurementstions in GIS "Map 2011" Yoshkar-Ola was dedicated "built-up Area of high-rise residential buildings". The parameters of the plots with trees: the number of elements of different levels, the square has an area and perimeter, the absolute and relative form. The obtained equations binomial rank distributions, conducted the ratings and selected the best area with trees on the environmental conditions

Key words: city, cadastral quarter, the stands, the distribution, patterns, rating, the best site with trees.

Введение. По классификации ООН [7] среди 11 классов почвенного покрова первые три составляют: травяной покров, древесно-кустарниковая растительность и леса. В городе им соответствуют три элемента растительного покрова: газоны, древесные насаждения (древостои) и кустарник обычный. Для выявления закономерностей была принята зонирование городской застройки и картографическими измерениями в ГИС «Карта 2011» была выделена «Зона застройки многоэтажными жилыми домами (58 кадастровых кварталов)».

В зоне застройки многоэтажными жилыми домами (58 кадастровых кварталов) были рассмотрены элементы растительности [1-6] только в виде древостоев (табл. 1).

Древостои имеют следующие параметры:

- количество элементов древостоев $n_{\partial}$, шт.;

- периметр земельного участка с деревьями $P_{\partial}$, м; 
- площадь земельного участка с деревьями $S_{\partial}, \mathrm{M}^{2}$;

- коэффициент абсолютной формы $s_{\partial}=S_{\partial} / P_{\partial}$;

- коэффициент относительной формы объекта $\gamma_{\partial}=100 S_{\partial} / P_{\partial}^{2}$.

Таблица 1

Параметры кадастровых кварталов зоны многоэтажных жилых домов с ранговыми местами по значениям параметров древостоев

\begin{tabular}{|r|c|c|c|c|c|c|c|c|c|c|}
\hline \multirow{2}{*}{$\begin{array}{c}\text { № } \\
\text { П/п }\end{array}$} & \multicolumn{7}{|c|}{ Параметры древостоя } & \multicolumn{5}{|c|}{ Параметр формы } \\
\cline { 2 - 11 } & $R_{n}$ & $n_{\partial}$, шт. & $R_{P}$ & $P_{\partial}, \mathrm{м}$ & $R_{S}$ & $S_{\partial}, \mathrm{M}^{2}$ & $R_{a s}$ & $S_{\partial}, \mathrm{M}$ & $R_{\gamma}$ & $\gamma_{\partial}, \%$ \\
\hline 1 & 21 & 39 & 15 & 4009 & 12 & 18747 & 11 & 4.68 & 26 & 0.1166 \\
\hline 2 & 46 & 0 & 46 & 0 & 46 & 0 & 46 & 0 & 46 & 0 \\
\hline 3 & 41 & 1 & 42 & 66 & 41 & 185 & 32 & 2.80 & 3 & 4.2304 \\
\hline 4 & 41 & 1 & 44 & 38 & 44 & 81 & 38 & 2.14 & 1 & 5.6728 \\
\hline 5 & 9 & 72 & 2 & 8374 & 2 & 44657 & 6 & 5.33 & 38 & 0.0637 \\
\hline & & & & & & & & & & \\
\hline
\end{tabular}

Ранговые распределения. Вектор предпорядка предпочтительности «лучше $\rightarrow$ хуже» у всех пяти факторов одинаков: чем больше, тем лучше (рис. 1).

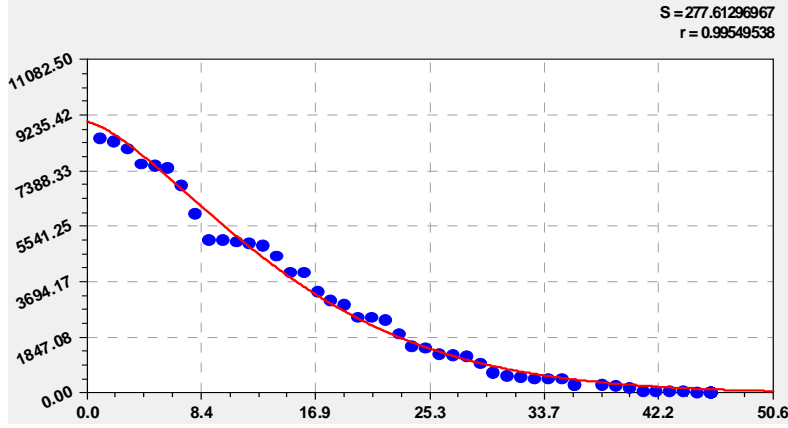

1) периметр древостоев

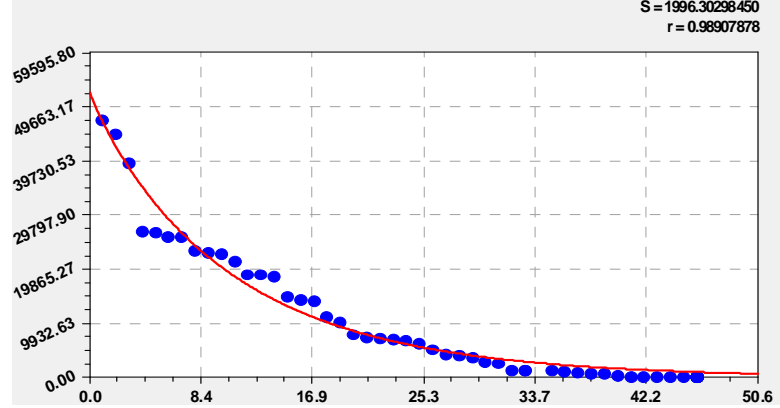

3) площадь древостоев

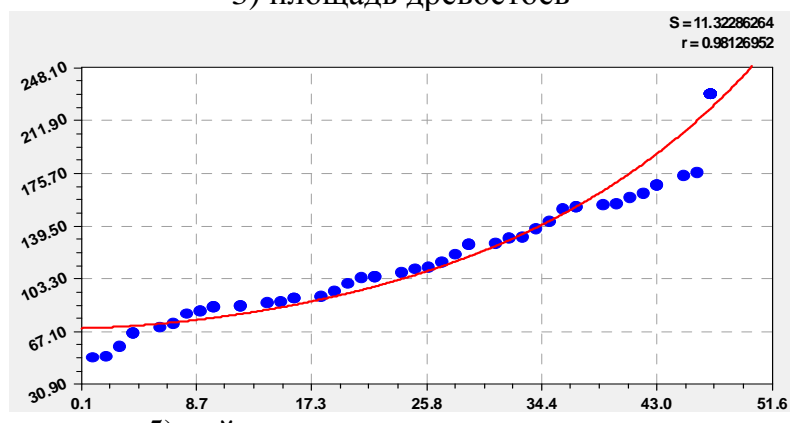

5) рейтинг кадастровых кварталов

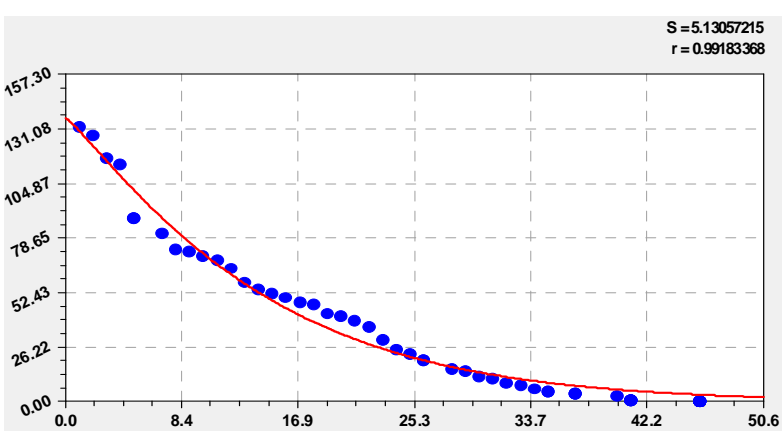

2) численность древостоев

$\mathrm{S}=0.22188067$

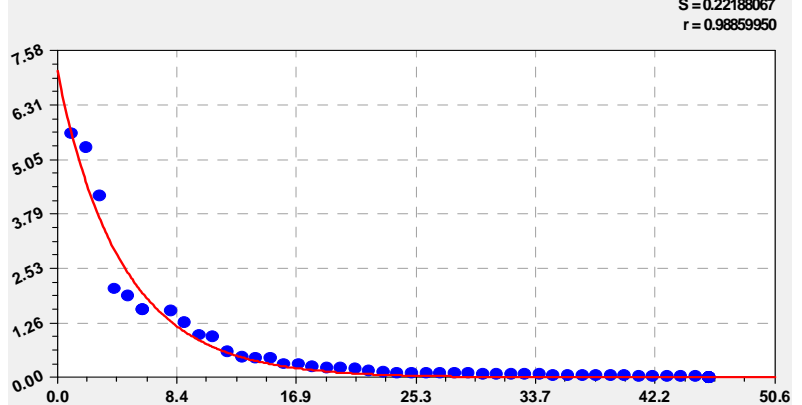

4) коэффициент относительной формы $S=0.76204516$
$r=0.93810994$

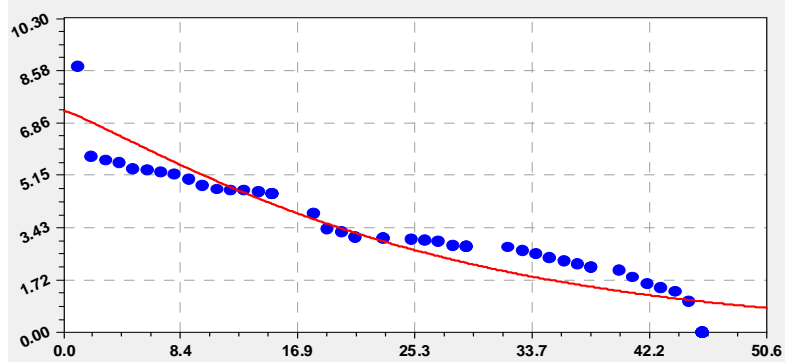

6) коэффициент абсолютной формы

Рис. 1. Графики ранговых распределений кадастровых кварталов по древостоям 
По пяти параметрам кадастровых кварталов и сумме рангов были получены уравнения ранговых распределений:

$$
\begin{gathered}
P_{\partial}=9011,3378 \exp \left(-0,017442 R_{p}^{1,43765}\right) ; \\
n_{\partial}=136,49955 \exp \left(-0,047978 R_{n}^{1,13372}\right) ; \\
S_{\partial}=52161,437 \exp \left(-0,11107 R_{S}^{0,93199}\right) ; \\
\gamma_{\partial}=7,10945 \exp \left(-0,22967 R_{\gamma}^{0,95344}\right) ; \\
\sum R=69,47528 \exp \left(0,0025332 I_{\kappa b}^{1,59004}\right) ; \\
S_{\partial}=7,27000 \exp \left(-0,02451 R_{a s}^{1,14525}\right) .
\end{gathered}
$$

Наиболее точно получается периметр древостоев, а с наибольшей погрешностью учитывается коэффициент абсолютной формы древостоев.

Рейтинг факторов по рангам. Без статистического моделирования можно выявить

\begin{tabular}{|c|c|c|c|c|c|c|c|c|}
\hline $\begin{array}{c}\text { № } \\
\text { ㅍ/ח }\end{array}$ & $\begin{array}{c}\text { Код кадастрового квартала зоны } \\
\text { застройки многоэтажными жилыми домами }\end{array}$ & $R_{n}$ & $R_{P}$ & $R_{S}$ & $R_{a s}$ & $R_{\gamma}$ & $\sum R$ & $I_{\kappa \beta}$ \\
\hline 1 & 12:05:0303001","",20110916,20110916,20120306,1,"",113638.3 & 21 & 15 & 12 & 11 & 26 & 85 & 12 \\
\hline 2 & 12:05:0702004","",20110916,20110916,20120306,1,"",80295.2 & 46 & 46 & 46 & 46 & 46 & 230 & 47 \\
\hline 3 & 12:05:0704005","",20110916,20110916,20120306,1,"",107571.1 & 41 & 42 & 41 & 32 & 3 & 159 & 41 \\
\hline$\ldots$ & $\cdots$ & $\cdots$ & $\cdots$ & $\cdots$ & $\cdots$ & $\cdots$ & $\cdots$ & $\cdots$ \\
\hline 36 & 12:05:0303006","',20110916,20110916,20120306,1,"'",208842.4 & 5 & $\mathbf{0}$ & $\mathbf{0}$ & 5 & 39 & 49 & 1 \\
\hline$\cdots$ & $\cdots$ & $\cdots$ & $\cdots$ & $\cdots$ & $\cdots$ & $\cdots$ & $\cdots$ & $\cdots$ \\
\hline 56 & 12:05:0503004","",20110916,20110916,20120306,1,"",186932.9 & 14 & 5 & 3 & 8 & 36 & 66 & 4 \\
\hline 57 & 12:05:0202004","",20110916,20110916,20120306,1,"",303214.2 & 3 & 8 & 13 & 21 & 40 & 85 & 12 \\
\hline \multirow[t]{3}{*}{58} & 12:05:0203003","",20110916,20110916,20120306,1,"",238141.1 & 2 & 12 & 18 & 37 & 41 & 110 & 25 \\
\hline & Сумма рангов $\sum R$ & 1571 & 1586 & 1586 & 1578 & 1586 & 7907 & - \\
\hline & Рейтинговое место показателя & 1 & 3 & 3 & 2 & 3 & - & - \\
\hline
\end{tabular}
значимость каждого из пяти факторов, а также определить рейтинг среди 58 кадастровых кварталов (табл. 2).

Таблица 2

Ранговые распределения параметров древостоев на кадастровых кварталах зоны многоэтажных жилых домов города Йошкар-Ола

Первое место получил кадастровый квартал №0303006. Суммированием по 58 строкам получаем рейтинг факторов. Как показатель на первом месте оказалась численность древостоев на кадастровом квартале.

Далее проведем факторный анализ участков с деревьями.

Исходные данные. Они приведены в таблице 3. В ней нулями показано отсутствие древостоя на этом земельном участке. Из пяти факторов получаются $5^{2}=25$ отношений, из которых пять являются закономерностями ранговых распределений. А $25-5=20$ формул характеризуют бинарные отношения между факторами. 
Значения параметров древостоев подзоны 11

\begin{tabular}{|c|c|c|c|c|c|}
\hline \multirow{2}{*}{$\begin{array}{c}\text { № } \\
\Pi / \Pi\end{array}$} & \multicolumn{3}{|c|}{$\begin{array}{l}\text { Параметры } \\
\text { древостоя }\end{array}$} & \multicolumn{2}{|c|}{$\begin{array}{c}\text { Параметр } \\
\text { формы }\end{array}$} \\
\hline & $n_{\partial}$, шт. & $P_{\partial}, \mathrm{M}$ & $S_{\partial}, \mathrm{M}^{2}$ & $S_{\partial}, \mathrm{M}$ & $\gamma_{\partial}, \%$ \\
\hline 1 & 39 & 4009 & 18747 & 4.68 & 0.1166 \\
\hline 2 & 0 & 0 & 0 & 0 & 0 \\
\hline 3 & 1 & 66 & 185 & 2.80 & 4.2304 \\
\hline 4 & 1 & 38 & 81 & 2.14 & 5.6728 \\
\hline 5 & 72 & 8374 & 44657 & 5.33 & 0.0637 \\
\hline$\ldots$ & $\cdots$ & $\cdots$ & $\cdots$ & $\cdots$ & $\cdots$ \\
\hline
\end{tabular}

Рейтинг факторов по коэффициентам корреляции. В таблице 4 приведены коэффициенты корреляции закономерностей.

Таблица 4

Корреляционная матрица и рейтинг факторов по детерминированным моделям

\begin{tabular}{|c|c|c|c|c|c|c|c|}
\hline \multirow{2}{*}{$\begin{array}{c}\text { Факторы } \\
\text { как объясняющие } \\
\text { переменные } x\end{array}$} & \multicolumn{5}{|c|}{ Факторы - показатели $y$} & \multirow{2}{*}{$\begin{array}{l}\text { Сумма } \\
\text { коэф. } \\
\text { корр. }\end{array}$} & \multirow{2}{*}{$\begin{array}{c}\text { Рейтинг } \\
I_{x}\end{array}$} \\
\hline & $n_{\partial}$, шт. & $P_{\partial}, \mathrm{M}$ & $S_{\partial}, \mathrm{M}^{2}$ & $S_{\partial}, \mathrm{M}$ & $\gamma_{\partial}, \%$ & & \\
\hline Численность $n_{\partial}$, шт. & 0,9918 & 0,8882 & 0,7832 & 0,2871 & 0,3979 & 3,3482 & 3 \\
\hline Периметр $P_{\partial}$, м & 0,8918 & 0,9955 & 0,9557 & 0,7391 & 0,3957 & 3,9778 & 1 \\
\hline Площадь $S_{\partial}$, м $^{2}$ & 0,7807 & 0,9657 & 0,9891 & 0,7902 & 0,3641 & 3,8898 & 2 \\
\hline Абсол. форма $s_{\partial}$, м & 0,5534 & 0,6437 & 0,5387 & 0,9381 & 0,0334 & 2,7073 & 4 \\
\hline Относит. форма $\gamma_{\partial}, \%$ & 0,4230 & 0,4200 & 0,2874 & 0,0334 & 0,9886 & 2,1524 & 5 \\
\hline Сумма коэфф. коррел. & 3,6407 & 3,9131 & 3,5541 & 2,7879 & 2,1797 & 16,0755 & - \\
\hline Рейтинг $I_{y}$ & 2 & 1 & 3 & 4 & 5 & - & 0,6430 \\
\hline
\end{tabular}

По рейтингу среди влияющих переменных на первом месте оказался периметр древостоя, на втором - площадь древостоя и на третьем - численность древостоев на кадастровом квартале. Как показатель на первом месте находится периметр, на втором - численность и на третьем месте - площадь земельного участка с деревьями.

Корреляционная матрица бинаров. Рассмотрим коэффициенты корреляции бинарных биотехнических закономерностей (табл. 5).

Таблица 5

Корреляционная матрица бинарных отношений факторов

\begin{tabular}{|c|c|c|c|c|c|}
\hline \multirow{2}{*}{$\begin{array}{c}\text { Факторы } \\
\text { как объясняющие } \\
\text { переменные } x\end{array}$} & \multicolumn{5}{|c|}{ Факторы - показатели $y$} \\
\hline & $n_{\partial}$, шт. & $P_{\partial}, \mathrm{M}$ & $S_{\partial}, \mathrm{m}^{2}$ & $s_{\partial}, \mathrm{M}$ & $\gamma_{\partial}, \%$ \\
\hline Численность $n_{\partial}$, шт. & & 0,8882 & 0,7832 & 0,2871 & 0,3979 \\
\hline Периметр $P_{\partial}$, м & 0,8918 & & 0,9557 & 0,7391 & 0,3957 \\
\hline Площадь $S_{\partial}$, м $^{2}$ & 0,7807 & 0,9657 & & 0,7902 & 0,3641 \\
\hline Абсол. форма $s_{\partial}$, м & 0,5534 & 0,6437 & 0,5387 & & 0,0334 \\
\hline Относит. форма $\gamma_{\partial}, \%$ & 0,4230 & 0,4200 & 0,2874 & 0,0334 & \\
\hline
\end{tabular}

Из 20 уравнений выбираем закономерности с допустимым уровнем адекватности по ко- 
эффициенту корреляции (рис. 2). Чаще всего выделяют сильные связи с коэффициентом корреляции $r \geq 0,7$, именно они считаются относительно надежными в расчетах.

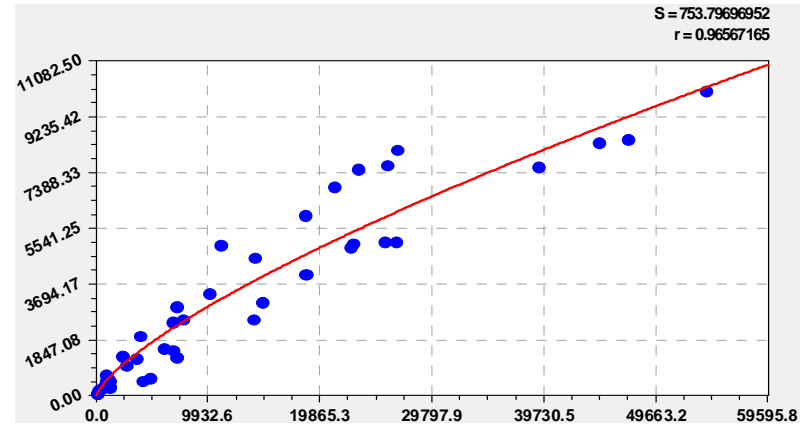

1) зависимость $-P_{\partial}=f\left(S_{\partial}\right)$

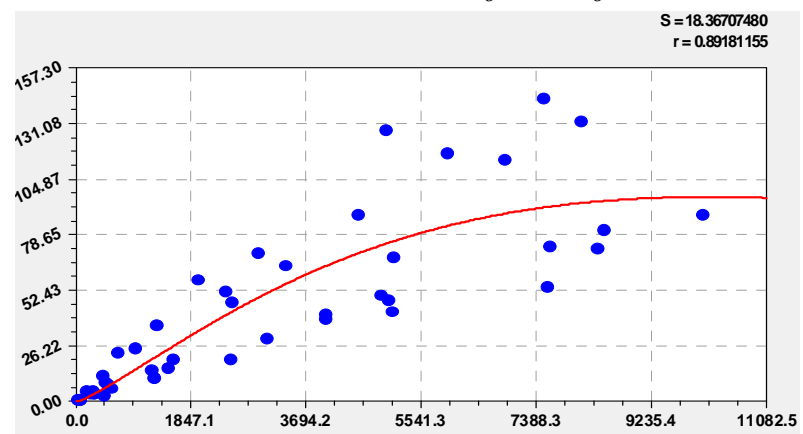

3) выражение $-n_{\partial}=f\left(P_{\partial}\right)$

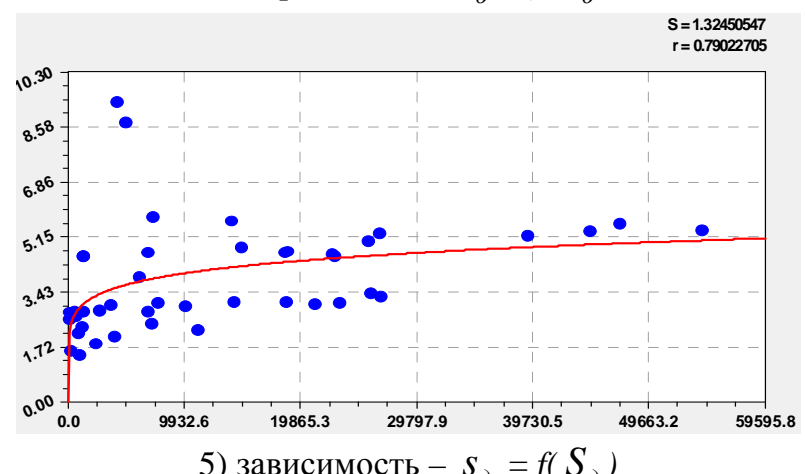

5) зависимость $-s_{\partial}=f\left(S_{\partial}\right)$

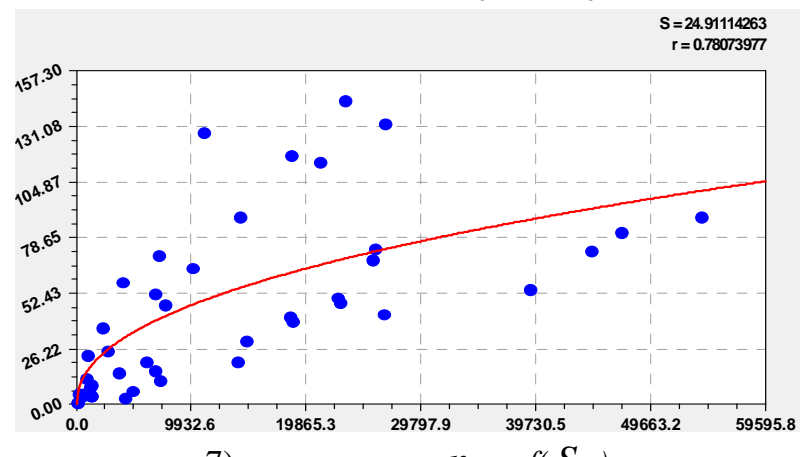

7) выражение $-n_{\partial}=f\left(S_{\partial}\right)$

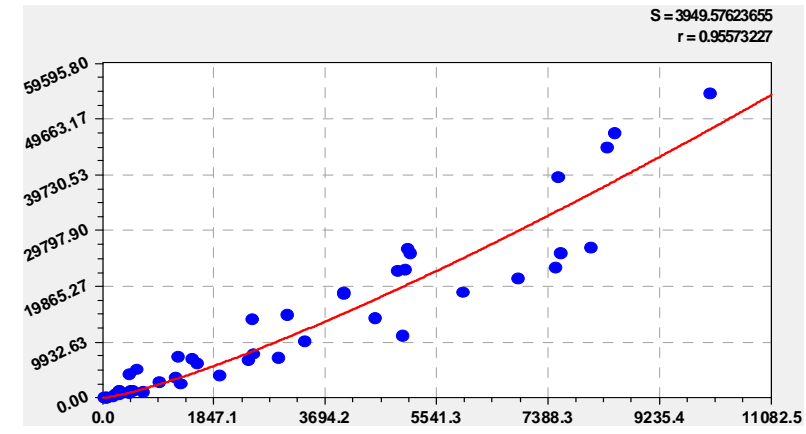

2) формула $-S_{\partial}=f\left(P_{\partial}\right)$

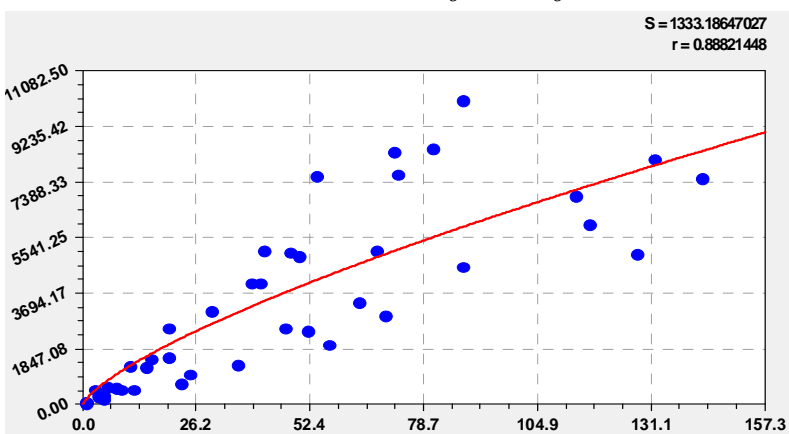

4) закономерность $-P_{\partial}=f\left(n_{\partial}\right)$

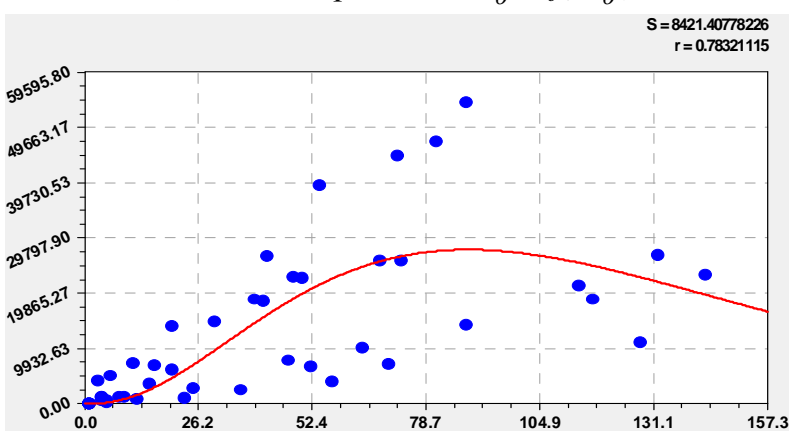

6) формула $-S_{\partial}=f\left(n_{\partial}\right)$

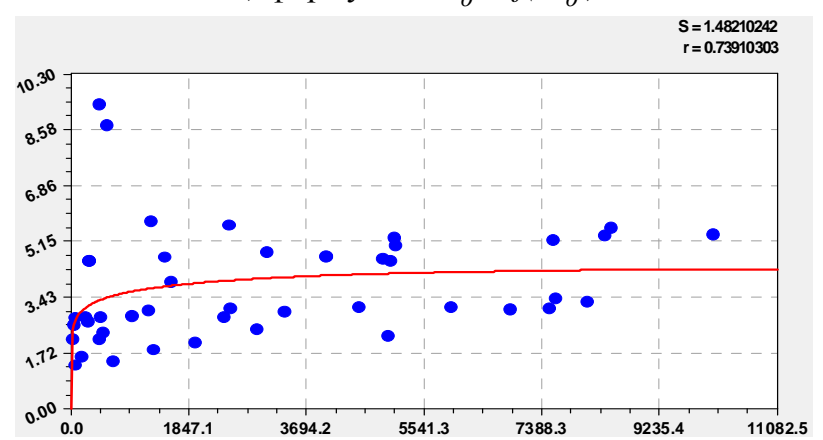

8) закономерность $-s_{\partial}=f\left(P_{\partial}\right)$

Рис. 2. Графики бинарных связей кадастровых кварталов по древостоям

Из 20 формул остались 8 уравнений (табл. 6 и табл. 7), имеющие тесноту связи по коэффициенту корреляции более 0,7 , то есть которые относятся к сильным связям. Поэтому они могут быть применены при составлении комплекса уравнений у имитационной модели поведения древостоев на кадастровых кварталах города. 
Корреляционная матрица по сильным бинарным связям при $r \geq 0,7$

\begin{tabular}{|c|c|c|c|c|c|}
\hline \multirow{2}{*}{$\begin{array}{c}\text { Факторы } \\
\text { как объясняющие } \\
\text { переменные } x\end{array}$} & \multicolumn{5}{|c|}{ Факторы - показатели $y$} \\
\hline & $n_{\partial}$, шт. & $P_{\partial}, \mathrm{M}$ & $S_{\partial}, \mathrm{M}^{2}$ & $S_{\partial}, \mathrm{M}$ & $\gamma_{\partial}, \%$ \\
\hline Численность $n_{\partial}$, шт. & & 0,8882 & 0,7832 & & \\
\hline Периметр $P_{\partial}$, м & 0,8918 & & 0,9557 & 0,7391 & \\
\hline Площадь $S_{\partial}$, м $^{2}$ & 0,7807 & 0,9657 & & 0,7902 & \\
\hline Абсол. форма $s_{\partial}$, м & & & & & \\
\hline Относит. форма $\gamma_{\partial}, \%$ & & & & & \\
\hline
\end{tabular}

Рейтинг бинарных отношений параметров древостоев

\begin{tabular}{|c|c|c|}
\hline $\begin{array}{c}\text { Влияние } \\
x \rightarrow y\end{array}$ & $\begin{array}{c}\text { Формула влияния } \\
\text { фактора } x \rightarrow y\end{array}$ & $\begin{array}{c}\text { Коэф. } \\
\text { корр. }\end{array}$ \\
\hline$S_{\partial}-P_{\partial}$ & $P_{\partial}=3,56584 S_{\partial}^{0,73047}$ & 0,9657 \\
\hline$P_{\partial}-S_{\partial}$ & $S_{\partial}=0,47163 P_{\partial}^{1,25062}$ & 0,9557 \\
\hline$P_{\partial}-n_{\partial}$ & $n_{\partial}=0,0028896 P_{\partial}^{1,26625} \exp \left(-0,00012574 P_{\partial}^{0,99894}\right)$ & 0,8918 \\
\hline$n_{\partial}-P_{\partial}$ & $P_{\partial}=227,92906 n_{\partial}^{0,72767}$ & 0,8882 \\
\hline$S_{\partial}-S_{\partial}$ & $S_{\partial}=1,17844 S_{\partial}^{0,13345}$ & 0,7902 \\
\hline$n_{\partial}-S_{\partial}$ & $S_{\partial}=4,53595 n_{\partial}^{2,50512} \exp \left(-0,028403 n_{\partial}\right)$ & 0,7832 \\
\hline$S_{\partial}-n_{\partial}$ & $n_{\partial}=0,74593 S_{\partial}{ }^{0,45025}$ & 0,7807 \\
\hline$P_{\partial}-s_{\partial}$ & $S_{\partial}=1,74926 P_{\partial}^{0,10707} \exp \left(-8,79382 \cdot 10^{-6} P_{\partial}\right)$ & 0,7391 \\
\hline
\end{tabular}

Статистическим моделированием параметров участков с деревьями можно найти биотехнические закономерности высокой адекватности.

Заключение. Среди лесных насаждений первое место получил участок №39 по 88 элементам, по рейтингу среди влияющих переменных на первом месте оказалась площадь древостоя, на втором - периметр участка с деревьями, как показатель на первом месте находится периметр древостоя, на втором - площадь земельного участка с деревьями.

\section{Список литературы}

1. Кудряшова А.И. Рейтинг земель Тульской области по районам // «Опыт прошлого взгляд в будущее» - 4-я Международная научно-практическая конференция молодых ученых и студентов. Материалы конференции: ТулГУ, Тула, 2014, С. 376-381.

2. Мазуркин П.М., Кудряшова А.И. Динамика онтогенеза листьев дерева. Йошкар-Ола: ПГТУ, 2015. 172 с.

3. Мазуркин П.М., Кудряшова А.И. Закономерности онтогенеза листьев деревьев. Динамика роста листьев липы и березы в чистой и загрязненной автомобильными выхлопами 
городской среде. Германия: LAB LAMBERT Academic Publishing, 2015. 100 c. ISBN 978-3659-68893-2.

4. Мазуркин П.М., Кудряшова А.И., Фадеев А.Н. Закономерности распределения кадастровых участков города Йошкар-Ола // Труды Поволжского ГТУ. Сер.: Технологическая. Вып. 3. Йошкар-Ола: ПГТУ, 2015. С.259-263.

5. Мазуркин П.М., Кудряшова А.И., Фадеев А.Н. Закономерности распределения кадастровых кварталов в общественно-деловой зоне города // Матер. междунар. научно-практ. конф. «Управление территорией: современные подходы и методы». Пенза: ПГУАС, 2015. С. $58-62$.

6. Мазуркин П.М., Кудряшова А.И., Фадеев А.Н. Вейвлет-анализ распределений центров кадастровых кварталов города // Землеустройство, кадастр и мониторинг земель. 2015. №8. c. 61-70.

7. G“unther Fischer, Harrij van Velthuizen, Mahendra Shah, Freddy Nachtergaele. Global Agro-ecological Assessment for Agriculture in the 21st Century: Methodology and Results. International Institute for Applied Systems Analysis, Laxenburg, Austria. Food and Agriculture Organization of the United Nations. Viale delle Terme di Caracalla. Rome, Italy, 2002. URL: http://webarchive.iiasa.ac.at/Research/LUC/SAEZ/index.html. 